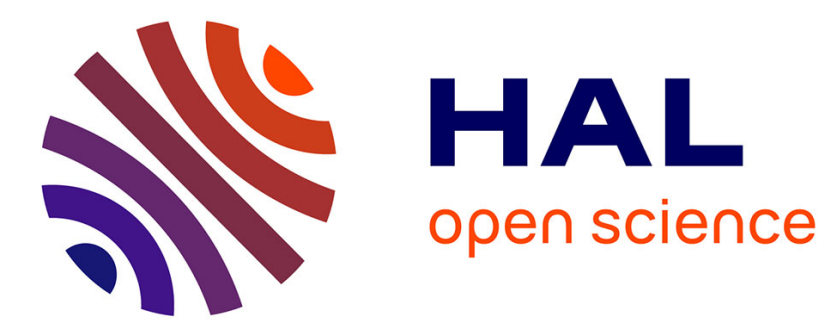

\title{
Supersonic jet spectroscopy of parent hemiporphycene: Structural assignment and vibrational analysis for S 0 and S 1 electronic states
}

Sebastian Peukert, Michal Kijak, Jakub Ostapko, Jerzy Sepiol, Catherine Le Bris, Anne Zehnacker-Rentien, Michal Gil, Jacek Waluk

\section{To cite this version:}

Sebastian Peukert, Michal Kijak, Jakub Ostapko, Jerzy Sepiol, Catherine Le Bris, et al.. Supersonic jet spectroscopy of parent hemiporphycene: Structural assignment and vibrational analysis for S 0 and S 1 electronic states. Journal of Chemical Physics, 2018, 149 (13), pp.134307. 10.1063/1.5048843 . hal-02070259

\section{HAL Id: hal-02070259 \\ https://hal.science/hal-02070259}

Submitted on 10 Feb 2020

HAL is a multi-disciplinary open access archive for the deposit and dissemination of scientific research documents, whether they are published or not. The documents may come from teaching and research institutions in France or abroad, or from public or private research centers.
L'archive ouverte pluridisciplinaire HAL, est destinée au dépôt et à la diffusion de documents scientifiques de niveau recherche, publiés ou non, émanant des établissements d'enseignement et de recherche français ou étrangers, des laboratoires publics ou privés. 


\title{
Supersonic Jet Spectroscopy of Parent Hemiporphycene: Structural
}

\section{Assignment and Vibrational Analysis for $S_{0}$ and $S_{1}$ Electronic States}

\author{
Sebastian Peukert, ${ }^{1 \#}$ Michat Kijak, ${ }^{1}$ Jakub Ostapko, ${ }^{1}$ Jerzy Sepiot, ${ }^{1}$ Catherine Le Bris, ${ }^{2}$ Anne \\ Zehnacker-Rentien ${ }^{2,3}$ Michat Gil, ${ }^{1 *}$ Jacek Waluk, ${ }^{1,4}$
}

${ }^{1}$ Institute of Physical Chemistry, Polish Academy of Sciences, Kasprzaka 44/52, 01-224

\author{
Warsaw, Poland; \\ ${ }^{2}$ CNRS, Institut des Sciences Moléculaires d’Orsay (ISMO); \\ ${ }^{3}$ Centre Laser Université Paris-Sud (CLUPS), University Paris-Sud, Orsay, France; \\ ${ }^{4}$ Faculty of Mathematics and Science, Cardinal Stefan Wyszyński University, Dewajtis 5, 01- \\ 815 Warsaw, Poland.
}

*Corresponding author: mgil@ichf.edu.pl

\begin{abstract}
Hemiporphycene (HPc), a constitutional isomer of porphyrin, is studied under supersonic expansion conditions by means of laser-induced fluorescence (LIF), visible-visible hole-burning experiments, single vibronic level fluorescence (SVLF) techniques, and quantum chemical calculations. Only one trans form of jet-cooled HPc is observed, in contrast with solutions studies that evidence a mixture of two trans tautomeric forms separated in energy by ca. $1 \mathrm{kcal} / \mathrm{mol}$. Reliable structural assignment is provided by simulating absorption and emission patterns at the DFT and TD-DFT levels of theory. The vibronic spectra are nicely reproduced for both electronic ground and lowest excited singlet states for the most stable trans form. In contrast with another porphyrin isomer, porphycene (Pc), no tunneling or photoinduced hydrogen transfer are detected. The lower symmetry of HPc compared with $\mathbf{P c}$ and the concomitant non-equivalent positions of the inner-cavity nitrogen atoms result in a nonsymmetric double minimum potential for tautomerization, larger energy barrier, and a longer tunneling distance, with the average intramolecular hydrogen bonds length larger in HPc than in Pc. HPc readily forms hydrates that show red-shifted absorption relative to the bare molecule.
\end{abstract}


Keywords: Tautomerism, Proton Transfer, Laser Induced Fluorescence, Dispersed Fluorescence, Tetrapyrrolic ring, Supersonic Expansion.

\#Present address: IVG, Institute for Combustion and Gas Dynamics-Reactive Fluids, University of Duisburg-Essen, 47057 Duisburg, Germany. 


\section{Introduction}

Porphyrin (Pr) is an aromatic system where four pyrrolic subunits are arranged into a macrocycle having a planar, rectangular cavity of four nitrogen atoms connected via two inner hydrogen bonds. Well-defined configuration of this cavity and relatively good protection of the inner H-bonds from the environment makes $\mathbf{P r}$ and its constitutional isomers interesting model systems for studying intramolecular hydrogen transfer. ${ }^{1-6}$ The rate of hydrogen transfer strongly depends on geometrical parameters of the inner cavity ( $\mathrm{NH}^{\cdots} \mathrm{N}$ distance and linearity). Special attention has been paid to porphycene (Pc), where the transfer of two internal hydrogens has been investigated in various environments by using multitude of stationary and time-resolved spectroscopic and microscopic techniques. ${ }^{3,4,7, ~ 8, ~ 9-27 ~}$ Tautomerization rates in Pc are larger than in $\mathbf{P r}$ by many orders of magnitude (picoseconds vs. microseconds). In Pc, the reaction takes place in both ground and excited electronic states. It proceeds via concerted movement of two hydrogen atoms along a symmetric double minimum on the potential energy surface, assigned to two isoenergetic trans tautomeric forms (Figure 1). The process has been found to be dominated by tunnelling, not only in isolated molecules at low temperatures, ${ }^{10,23-25}$ but also in room temperature solutions, as demonstrated by ultrafast transient absorption anisotropy measurements. ${ }^{16}$ Laser-induced fluorescence and dispersed fluorescence spectra recorded under jet-cooled conditions clearly exhibit the band splitting, characteristic of coherent delocalization of two inner hydrogens, ${ }^{23,24,26,27}$ in contrast with Pr that exhibits single bands. ${ }^{28}$ The splitting is strongly sensitive to deuteration, confirming the tunnelling nature of the process. Moreover, tunnelling splitting in Pc is vibrational-mode selective, due to the multidimensional nature of the reaction coordinate. ${ }^{24-27}$ The sensitivity to structural perturbations, such as substitution ${ }^{24}$ or deuteration of the peripheral rim $^{26}$ pointed out the importance of weak structural perturbations or symmetry breaking in the process. Supersonic jet studies of tetraalkyl-substituted Pc have shown the distortion of the PES caused by four methyl or $n$-propyl groups. ${ }^{24}$ The energy 
degeneracy of the tautomeric forms can be lifted by asymmetric chemical substitution of formerly symmetric framework, e.g., a single substitution at one of the meso positions ($\mathrm{CH}=\mathrm{CH}$ - bridges between bipyrrole subunits). Such an effect of the PES distortion has been reported for tetra- $n$-propyl porphycene singly substituted at the meso position with an acetoxy group. ${ }^{29,30}$ The studies carried out in condensed media at different temperatures have shown the presence of two almost isoenergetic non-equivalent trans tautomers. While the PES in the ground electronic state is only slightly asymmetric, resulting in comparable populations of both tautomers even at cryogenic temperatures down to $\sim 20 \mathrm{~K}$, that of the excited electronic state is strongly asymmetric. Thus, the emission of only one tautomer has been detected, due to fast exoenergetic excited-state hydrogen transfer in the $\mathrm{S}_{1}$ state. Quite different behavior has been reported for 9-amino-substituted tetraphenylporphycene, although the potential-energy surface is also almost symmetric in the ground state and strongly asymmetric in $\mathrm{S}_{1}$. In this case, dual emission is observed from the non-equivalent trans tautomers. ${ }^{31,32}$

\section{Figure 1}

Other porphyrin isomers obtained so far include corrphycene, ${ }^{33,34}$ hemiporphycene, ${ }^{35,}$ 36 isoporphycene, ${ }^{37}$ inverted (confused), ${ }^{38,}, 39$ and neo-confused ${ }^{40}$ porphyrins. Except for inverted porphyrin, all these isomers have been obtained so far as substituted derivatives. Recently, Ostapko et al. achieved the synthesis of hemiporphycene (HPc) in its parent, unsubstituted form. ${ }^{41}$ HPc is of lower symmetry $\left(C_{s}\right)$ than $\operatorname{Pr}\left(D_{2 h}\right)$ and $\operatorname{Pc}\left(C_{2 h}\right)$ and therefore, in contrast to $\mathbf{P r}$ and $\mathbf{P c}$, its trans forms are not equivalent. Figure 1 shows the structure of two trans tautomers in Pc and in HPc, and the schematic plots of their potential energy surfaces along the hydrogen transfer coordinate. Trans 1 form of HPc is theoretically predicted as the most stable one in the ground electronic state at the B3LYP/6-311++G(d,p) level, while the energy of trans 2 is higher by $\sim 1 \mathrm{kcal} / \mathrm{mol}$. This calculated value is in excellent agreement with electronic absorption and fluorescence measurements. UV/Vis absorption spectra of HPc in 
dodecane recorded as the function of temperature indicate the presence of two inequivalent forms, assigned to trans 1 and trans 2 tautomers. ${ }^{41}$ Fluorescence from both trans forms is observed upon excitation of the higher energy trans 2 tautomer and the rate of $\sim 10^{7} \mathrm{~s}^{-1}$ for trans 2 $\rightarrow$ trans 1 reaction has been estimated at room temperature. At $293 \mathrm{~K}$, the efficiency of trans 2 $\rightarrow$ trans 1 phototautomerization is low $(\sim 10 \%)$, but increases to $\sim 50 \%$ at $373 \mathrm{~K}$. The rate at room temperature is four orders of magnitude lower than the rate determined for $\mathrm{S}_{1}$ tautomerization in Pc, but still larger than that in Pr. ${ }^{15,42}$ This finding agrees with the results of electronic structure calculations of bare HPc and the crystal structure analysis of $\mathbf{H P c} \mathbf{c}^{41}$ and its octaethyl derivative, ${ }^{36}$ which confirm the planarity of the hemiporphycene framework and demonstrate that the dimensions of the inner cavity in HPc lie between those of Pc and Pr.

Combining the energy difference between trans 1 and trans 2 with the $0-0$ transition energies of both tautomers leads to the conclusion that the distortion of the potential is larger in the ground than in the excited state, although trans 1 remains the lower energy form in both $\mathrm{S}_{0}$ and $\mathrm{S}_{1 .}{ }^{41}$ Thus, the distortion of inner cavity due to a less symmetrical framework affects the potential energy surface differently than substitutions in meso position discussed above. This finding may be important for future synthesis, in designing new derivatives or isomers.

Supersonic jet technique combined with laser spectroscopy has proved to be very useful for studying tautomerism in porphycene derivatives, owing to highly selective excitation of a well-defined ground state population of cold and isolated molecules..$^{23,24,26,27}$ In the present work, we report and discuss experiments for HPc, applying this technique in combination with laser-induced fluorescence excitation (LIF) and single vibronic level fluorescence (SVLF), as well as visible-visible fluorescence depletion spectroscopy. The ground and electronic excited state geometries and harmonic frequencies are calculated within the frame of the density functional theory (DFT). 
The main purpose of this work is to confirm the structure of the lowest energy tautomeric form of HPc under conditions of molecular isolation. The computed difference in energy, $1 \mathrm{kcal} / \mathrm{mol}$, is at the limit of the accuracy of DFT calculations. A question arises whether the influence of the surroundings could not modify this difference. Moreover, if the difference in energy between trans 2 and trans 1 decreases under jet-cooled conditions, tunnelling splitting should be observed.

Next, even if the ground-state potential well is asymmetric in $\mathrm{S}_{0}$, one can ask the question whether it is possible to observe two tautomeric forms under jet-cooled conditions. Indeed, the relative population of conformers in a supersonic expansion depends not only on their energy difference, but also on the barrier separating the two potential wells. It might happen that kinetic trapping allows stabilization of higher-energy forms, even though the ground state energy difference of ca. $1 \mathrm{kcal} / \mathrm{mol}$ seems to exclude at first sight the possibility of populating the higher energy trans 2 tautomer in $\mathrm{S}_{0}$. The trans 2 form could also be formed in the electronically excited state. Condensed-phase studies have shown that phototautomerization proceeds in the trans $2 \rightarrow$ trans 1 direction only, which indicate that trans 1 is more stable in $\mathrm{S}_{1}$ as well. However, in a jet, the reverse trans $1 \rightarrow$ trans 2 process could take place upon excitation of a long-lived higher-energy $\mathrm{S}_{1}$ vibronic level of trans 1 .

We therefore undertake the study of HPc in isolated conditions and show that the analysis based on comparison between the measured and simulated LIF and SVLF spectra provides reliable arguments for the determination of the observed tautomeric structure. We also report the effect of hydration on the vibronic spectra of HPc.

\section{Experimental and Theoretical Methods}


In Warsaw, experiments in a supersonic expansion were performed using a home-made setup described previously. ${ }^{43}$ The samples were heated up to $\sim 520 \mathrm{~K}$ under the flow of helium (stagnation pressure of $\sim 3.5 \mathrm{~atm}$ ) used here as a carrier gas. A cold trap was used to freeze out water traces and the gas supply system has been purged with carrier gas. The gas mixtures were expanded to a vacuum chamber through a home-made pulsed valve (based on IOTA Series 9, General Valve) with a nozzle of $500 \mu \mathrm{m}$ diameter. The jet was probed by a laser beam at $8 \mathrm{~mm}$ downstream from the nozzle. A narrow band $\left(<0.1 \mathrm{~cm}^{-1}\right)$ optical parametric oscillator $(\mathrm{OPO}$, Sunlite Ex, Continuum) pumped by a seeded Powerlite $8000 \mathrm{Nd}$ :YAG laser (at $10 \mathrm{~Hz}$ repetition rate) was used with average pulse energy in the range of $0.2-1 \mathrm{~mJ}$.

The total fluorescence from the sample was collected by a toroidal mirror and focused through a RG645 nm long pass filter onto a cooled Hamamatsu R2949 photomultiplier connected to a Yokogawa DL9140 oscilloscope for the LIF measurements or, to a slit of an Acton Research 0.275 m (1200 lines/mm) spectrograph equipped with a Princeton Research LN-cooled CCD for measuring SVLF spectra. ${ }^{44}$

For fluorescence depletion spectroscopy, a homemade dye laser (Rh6G dye in methanol, energy $\sim 100 \mu \mathrm{J}$, spectral width $\sim 0.2 \mathrm{~cm}^{-1}$ ) pumped by a Nd:YAG laser (Surelite I-10, Continuum) was used as a pump, while the OPO served as a probe with a pump - probe delay of $200 \mathrm{~ns}$. In our procedure, the pump laser was fixed at a wavelength resonant with a vibronic transition of a selected species while scanning the probe laser. The measurement is done in the presence and absence of the pump laser beam by using a rotary shutter at each step of the scan, which results in two LIF excitation spectra (a so-called active baseline procedure).

After a few hours of heating we have observed thermal degradation of HPc. In order to exclude the possibility that thermal decomposition of the sample has an impact on the spectroscopy, LIF and SVLF spectra of HPc were also measured in Orsay using the laser desorption technique. Molecules were desorbed by laser pulses (frequency doubled Nd:YAG; 
Quantel, Brilliant B) from the surface of a graphite pellet fixed at the nozzle of a pulsed valve generating the supersonic jet. In these experiments argon was used as a carrier gas and expanded under a backing pressure of $\sim 5 \mathrm{~atm}$. LIF spectra were obtained by exciting the jet-cooled molecules by a tunable dye laser (Rh610 and Rh640 dyes, spectral width $\sim 0.2 \mathrm{~cm}^{-1}$ at $603 \mathrm{~nm}$ ) pumped by the second harmonic of a Nd:YAG laser. The fluorescence signal from the sample was collected by a two-mirror system and a monochromator (Princeton Instruments Acton SP2300) used under broad band conditions and then detected by a photomultiplier tube. The light collected and focused by the first mirror (a toroidal mirror, protected Aluminium, radius of curvature $\mathrm{R}-478.76, \mathrm{r}-422.89$, angle of incidence $20^{\circ}$ ) located at $700 \mathrm{~mm}$ from the fluorescent molecules that act as a point source. The light collected by the toroidal mirror was propagated onto a rotating planar mirror (coated BK7) and then reflected onto the entrance slit of a monochromator. The position (distance and rotation angle) of the planar mirror were carefully adjusted so that the emitted light was focused exactly on the entrance slit of the monochromator. For recording SVLF spectra, the fluorescence light was dispersed through this monochromator with a grating of 1200 lines/mm and the light was detected with an intensified and gated CCD (Princeton Instruments PI-MAX 4). ${ }^{44}$

Quantum chemical modeling was performed using the GAUSSIAN09 program package. ${ }^{45}$ Ground and excited state geometries were optimized and vibrational frequencies were calculated with DFT and TDDFT methods, respectively, applying the B3LYP functional and the $6-311++\mathrm{G}(\mathrm{d}, \mathrm{p})$ basis set. Vibrational frequency scaling factor of 0.969 has been used for both the ground and excited states. Vibrationally-resolved absorption and emission spectra were obtained by applying the Franck-Condon principle within the harmonic approximation, as implemented in Gaussian09. The half-widths of the bands, 1 and $15 \mathrm{~cm}^{-1}$, respectively, have been arbitrarily chosen to match the experimental ones. 


\section{Results and Discussion}

Lower symmetry of HPc relative to Pc increases the number of possible tautomeric forms obtained by moving the inner hydrogen atoms within the nitrogen cavity. Two trans and four cis forms can be envisaged. Table S1 (Supporting Information) contains the calculated relative energies of these isomers in $\mathrm{S}_{0}$ and $\mathrm{S}_{1}$ states. The calculations predict trans 1 to be the most stable form of isolated HPc in both $\mathrm{S}_{0}$ and $\mathrm{S}_{1}$. The second most stable form is trans2, higher in energy by 0.97 (0.89 with ZPVE correction) $\mathrm{kcal} / \mathrm{mol}$ in $\mathrm{S}_{0}$ and by $0.71(0.73)$ $\mathrm{kcal} / \mathrm{mol}$ in $\mathrm{S}_{1}$. The lower-energy cis form, cis 1 , is in $\mathrm{S}_{0} \sim 4-4.5 \mathrm{kcal} / \mathrm{mol}$ less stable than trans1. Therefore, all possible cis forms are unlikely to be observed under jet-cooled conditions and hence will not be considered further.

It was established for different symmetrically substituted Pc derivatives that proton transfer rates clearly correlate with the distances between $\mathrm{H}$-bonded $\mathrm{N}$-atoms. ${ }^{17}$ Our DFT calculations show that in HPc these distances are: $\mathrm{d}_{\mathrm{N} 1-\mathrm{N} 2} \sim 260.4$ and $259.5 \mathrm{pm}$, and $\mathrm{d}_{\mathrm{N} 3-\mathrm{N} 4} \sim$ 293.7 and $293.0 \mathrm{pm}$, for trans 1 and trans 2 forms, respectively. They are, on average, inbetween those of $\operatorname{Pr}\left(\mathrm{d}_{\mathrm{N}-\mathrm{N}} \sim 293.2 \mathrm{pm}\right)$ and $\operatorname{Pc}\left(\mathrm{d}_{\mathrm{N} 1-\mathrm{N} 2}=\mathrm{d}_{\mathrm{N} 3-\mathrm{N} 4} \sim 265.5 \mathrm{pm}\right)$, although a lower symmetry of HPc makes the situation more complicated. In turn, the average distance for transfer of two protons (calculated as $\left.\left[\left(\mathrm{d}_{\mathrm{N} 1-\mathrm{H}}-\mathrm{d}_{\mathrm{N} 2 \cdots \mathrm{H}}\right)+\left(\mathrm{d}_{\mathrm{N} 3 \cdots \mathrm{H}}-\mathrm{d}_{\mathrm{N} 4-\mathrm{H}}\right)\right] / 2\right)$ is much larger in $\mathbf{H P c}$ than in Pc for both, $\mathrm{S}_{0}$ - and $\mathrm{S}_{1}$-optimized structures (being 90.3 and $95.2 \mathrm{pm}$ in trans 1 of $\mathbf{H P c}$, and 65.5 and $69.1 \mathrm{pm}$ in trans tautomer of $\mathbf{P c}$, in $\mathrm{S}_{0}$ and $\mathrm{S}_{1}$ states, respectively). Therefore, we expect that in HPc the tautomerization rate will be larger than in Pr but lower than in Pc.

The LIF spectrum of HPc presented in Figure 2 consists of well-resolved bands in the measured spectral range, indicating sufficient cooling conditions in the jet. The half-width of the bands is $\sim 1 \mathrm{~cm}^{-1}$ and similar for spectra recorded using an oven and helium carrier gas or laser desorption and argon. The origin of the spectrum (0-0 transition) consists of a single band at $16566 \mathrm{~cm}^{-1}$, and, in comparison to Pc, is shifted to higher energies by $400 \mathrm{~cm}^{-1}$. No doublet 
structure characteristic for tunneling splitting is observed, which contrasts with Pc. The absence of "hot" bands was checked by varying the distance between the jet nozzle and the exciting laser beam from 5 to $11 \mathrm{~mm}$. No modification of the spectrum was observed. Besides vibronic bands that could be clearly assigned (see below), the spectrum contains several weak bands in the low frequencies region $\left(0-100 \mathrm{~cm}^{-1}\right)$ above the origin. Neither the LIF spectrum of bare Pc, nor that of Pr has shown transitions in this region. ${ }^{23,28}$ The presence of these bands could be an indication of the presence of several species, or be due to a more complex vibronic pattern caused by lower symmetry. Thus, to determine how many species are present in the jet, we conducted visible-visible double-resonance fluorescence depletion experiments. Figure 2 shows that all intense bands respond with similar relative depletion $(35-50 \%)$ as the $0-0$ band $(\sim 40 \%)$ of HPc. The same set of spectral dips was obtained while pumping the vibronic transitions at 138 , and at $142 \mathrm{~cm}^{-1}$ (not shown). This indicates that only one conformer of bare HPc is present in the $\mathrm{S}_{0}$ state in the jet. This observation agrees with previously-reported temperature dependence of the absorption spectra of HPc in solution, which showed a disappearance of the absorption band assigned to trans 2 tautomer upon lowering the temperature. ${ }^{41}$ It seems safe to assume that the trans 1 form remaining in the condensed media upon lowering the temperature is also the one present in the cold jet. One can notice in the LIF spectrum several bands separated by a few wavenumbers, for example at 138/142, 255/257, or $471 / 475 \mathrm{~cm}^{-1}$. In contrast to tunneling doublets observed for $\mathbf{P c}$, these bands respond as spectral dips to a common probe wavelength in the hole-burning experiment. Therefore, they are due to one form of HPc excited from a common vibrational level of the ground state and are due to excitation of vibronic bands with similar frequencies in $\mathrm{S}_{1}$, as will be seen later.

Figure 2

The identification of the tautomeric form observed in the LIF spectrum can be supported by modeling. First, we compared the frequencies of the experimental transitions with the 
calculated ones for the fundamental vibrations of the two trans tautomers. These comparisons result in equally good linear fits for both forms with root mean square errors of $\sim 4 \mathrm{~cm}^{-1}$ for trans 1 and $\sim 5 \mathrm{~cm}^{-1}$ for trans 2 . Based only on the calculated frequencies, it is therefore not possible to clearly conclude which tautomer is observed in the experiments. Consequently, we also analyzed the experimental and simulated intensity patterns. Figures 3 and 4 show the comparison between the experimental LIF and SVLF spectra of HPc and the theoretically predicted ones. In both spectra of Figure 3 and 4, the calculated intensities of the 0-0 transitions are very large in comparison to other bands. Very similar vibrational frequencies are observed in absorption and emission (compared in Table 1), and within the limitation imposed by a different resolution of both spectra, the dispersed fluorescence resembles relatively well a mirror image of the LIF spectrum. In particular, strong transitions due to in-plane fundamental vibrations $1 \mathrm{~A}^{\prime}-5 \mathrm{~A}^{\prime}$ and some of their combinations (e.g. $\left.1 \mathrm{~A}^{\prime}+5 \mathrm{~A}^{\prime}, 2 \mathrm{~A}^{\prime}+5 \mathrm{~A}^{\prime}\right)$ are observed both in LIF and SVLF. This observation supports lack of excited state tautomerization reaction upon the lowest energy (0-0 transition) excitation; a result expected from energy levels considerations (Figure 1).

\section{Figures 3-4}

Table 1

In the experimental LIF spectrum (Figure 3), the prominent vibronic bands at 138 and $142 \mathrm{~cm}^{-1}$ can be assigned to skeletal in-plane vibrations with similar predicted frequencies $\left(1 \mathrm{~A}^{\prime}\right.$ and $2 \mathrm{~A}^{\prime}$ modes) for both tautomers. They have comparable intensities, which is much better reproduced by calculations for the trans 1 tautomer. The experimental bands at 255 and $257 \mathrm{~cm}^{-}$

${ }^{1}$ can be assigned to the $3 \mathrm{~A}^{\prime}$ in-plane vibration calculated at $256 / 255 \mathrm{~cm}^{-1}$ for trans 1 and trans 2 and to a combination of two out-of-plane modes at $257 \mathrm{~cm}^{-1}$, respectively. In the simulated spectra, only the former transition has significant intensity, comparable for both tautomers. Thus, we extended the analysis by including Herzberg-Teller contributions in the simulation 
of the spectra (Figure S1, Supporting Information). This attempt did not improve the agreement between the experiment and theory in the region $0-500 \mathrm{~cm}^{-1}$ above the $0-0$ transition. In particular, an experimental doublet at $255 / 257 \mathrm{~cm}^{-1}$ was still not reproduced in LIF simulation regardless of chosen tautomer. A more precise diagnostic can be a triplet structure appearing in the experiment at 276,280 , and $284 \mathrm{~cm}^{-1}$, with an approximate intensity ratio of $1 / 2 / 1$. These bands are readily assigned as the overtones of $1 \mathrm{~A}^{\prime}$ and $2 \mathrm{~A}^{\prime}$ modes and their combination (1A' $\left.+2 A^{\prime}\right)$. The spectrum simulated for trans 1 reproduces this sequence of harmonics and combination with three bands at 270,278 , and $286 \mathrm{~cm}^{-1}$, which is not the case for the trans 2 tautomer. The bands observed at 293, 333, 355, and $375 \mathrm{~cm}^{-1}$ are assigned to in-plane fundamental vibrations $4 A^{\prime}-7 A^{\prime}$, respectively. The simulation predicts them to be observed in the spectrum regardless of the chosen tautomer, although their intensity ratio is slightly better reproduced in the case of trans 1 . Confirmation of the assignment to the trans 1 structure is given by the analysis of the vibronic transitions at 471,475 and $484 \mathrm{~cm}^{-1}$. These bands are due to the combinations of $1 \mathrm{~A}^{\prime}+5 \mathrm{~A}^{\prime}\left(138\right.$ and $\left.333 \mathrm{~cm}^{-1}\right), 2 \mathrm{~A}^{\prime}+5 \mathrm{~A}^{\prime}\left(142\right.$ and $\left.333 \mathrm{~cm}^{-1}\right)$, and the fundamental 9A' mode. The simulation for trans 1 shows bands at $464(135+329), 472(143+$ 329), and $476 \mathrm{~cm}^{-1}$ with relative intensities similar to those observed in the experiment. Again, the higher energy tautomer shows worse agreement in this respect. Thus, the above comparison of the experimental and simulated LIF spectra clearly is in favor of trans 1 tautomer as the species observed in the supersonic jet.

Comparison between experimental and simulated SVLF spectra confirms this assignment. Upon excitation at the 0-0 transition (Figure 4), the experimental spectrum shows four fluorescence bands in the region $0-400 \mathrm{~cm}^{-1}$, at 140, 258 (weak), 291, and $336 \mathrm{~cm}^{-1}$. For the band at $140 \mathrm{~cm}^{-1}$, we assign it to fundamental in-plane vibrations 1A' and 2A', calculated at 135 and $145 \mathrm{~cm}^{-1}$, but unresolved in the experiment due to insufficient resolution of SVLF spectra. Other three fluorescence bands in this region are assigned to $3 \mathrm{~A}^{\prime}, 4 \mathrm{~A}^{\prime}$, and $5 \mathrm{~A}^{\prime}$ in- 
plane modes (Table 1). Comparison between the experiment and the calculations for both trans tautomers shows that trans 1 gives better prediction with respect to the relative intensities of these four bands. An even stronger suggestion in favor of trans 1 tautomer is provided by the next group of four bands at $\sim 712,749,788$, and $818 \mathrm{~cm}^{-1}$. They are assigned to fundamental modes $12 \mathrm{~A}^{\prime}, 13 \mathrm{~A}^{\prime}, 15 \mathrm{~A}^{\prime}$, and $16 \mathrm{~A}^{\prime}$. These bands have practically no predicted intensity in the simulation for trans 2 , while they show excellent agreement with the spectrum of the trans 1 form. The next hint comes from a medium intensity experimental transition at $1167 \mathrm{~cm}^{-1}$ which in the simulation of the transl tautomer is predicted as an intense fundamental in-plane vibrational transition at $1188 \mathrm{~cm}^{-1}$. According to calculations, this mode strongly engages inplane wagging of the hydrogen atom in the $\mathrm{N} 1-\mathrm{H}$ bond, the one which is simply absent in the structure of trans2 (Figure 1). In the latter, the calculated frequency of the corresponding mode is considerably shifted, to $1231 \mathrm{~cm}^{-1}$, and the predicted intensity is much lower than that observed in the experiment. Between $1300-1400 \mathrm{~cm}^{-1}$, four relatively weak bands are observed at $1313,1343,1396$, and $1416 \mathrm{~cm}^{-1}$. While a definite assignment is difficult due to a multitude of skeletal in-plane vibrations predicted for this region, only the simulation for the trans 1 form shows significant fluorescence intensity in this region. Finally, a fluorescence band at $1606 \mathrm{~cm}^{-}$ ${ }^{1}$ is assigned to the in-plane fundamental mode calculated at $1583 \mathrm{~cm}^{-1}$ in the trans 1 tautomer. In contrast, the simulated spectrum for trans 2 does not show significant intensity bands above $1500 \mathrm{~cm}^{-1}$. Visualization of this vibration in trans 1 indicates a large displacement vector of the hydrogen atom bonded to N3. This particular bond is absent in the case of trans 2 which, in parallel to the explanation presented above for the band observed at $1167 \mathrm{~cm}^{-1}$, could be a reason for a worse agreement with experiment.

Based on the above analysis, one can safely conclude that it is the trans 1 tautomer which is observed in the supersonic jet. Consequently, the calculated frequencies of this form have been used for the assignment of vibronic bands in the experimental LIF and SVLF spectra in 
Table 1. Moreover, the fact that the emission spectrum is also characteristic of trans 1 experimentally confirms that it is also the most stable one in $\mathrm{S}_{1}$.

Previous experiments in solutions have suggested that the endothermic trans $1 \rightarrow \operatorname{trans} 2$ reaction could take place when increasing the excitation energy. This process is however difficult to follow in solution due to an overlap of broad absorption bands of both trans forms. The latter obstacle is not present in the jet, where only the trans 1 tautomer is present. In search of any evidence of phototautomerization, we compared in Figure 5 the SVLF spectra obtained upon excitation at the origin $\left(0-0\right.$ transition at $\left.16566 \mathrm{~cm}^{-1}\right)$ with those recorded using an excess of excitation energy (the respective transitions are marked in Figure 2). All spectra are background-corrected by subtracting the scattered light measured without seeding HPc into the jet stream. Due to uncertainties in this procedure, which in some cases leads even to a negative band in the corrected spectra, the intensities at the exact wavelength of excitation should be taken with care. The upper spectrum in Figure 5 was excited at the 0-0 transition. Due to slightly better $\mathrm{s} / \mathrm{n}$ ratio than the corresponding part of Figure 4 , it reveals two additional weak transitions at 477 and $\sim 610 \mathrm{~cm}^{-1}$, nicely predicted in the simulation of the trans 1 form (Figure 4, middle panel). When using an excess of excitation energy at the $(0-0)+138,142,293$, and $333 \mathrm{~cm}^{-1}$, the sequences built on "pseudo 0-0" transitions are the same as upon the lowest energy excitation. This is also true for SVLF spectra recorded upon excitation of other bands (not shown). The SVLF spectra presented in Figure 5 do not show any indication of fluorescence emission from two tautomeric forms. However, due to lower resolution and sensitivity of dispersed fluorescence, the possibility of tautomerization in the $S_{1}$ state with very small yield cannot be completely excluded.

Figure 5

As mentioned above, the LIF spectrum presented in Figure 2 shows some additional weak bands in the region $0-100 \mathrm{~cm}^{-1}$ above the origin of bare HPc, which do not respond as 
spectral dips in the fluorescence depletion spectrum. In turn, their intensity is growing upon addition of $\mathrm{H}_{2} \mathrm{O}$ vapors to the carrier gas. Thus, they are due to water remaining in the gas supply system, which leads to formation of $\mathbf{H P c} / \mathrm{H}_{2} \mathrm{O}$ complexes. Formation of complexes of porphycene with water has been reported by our group. ${ }^{23}$ A spectral signature of such species was observed as a LIF band at $+119 \mathrm{~cm}^{-1}$ above the $0-0$ transition of bare $\mathbf{P c}$, with the intensity dependent on the content of water admixed to helium gas. The SVLF spectrum (not published) recorded upon excitation into this band at $16294 \mathrm{~cm}^{-1}$ revealed a disappearance of doublet structures assigned to the tunneling splitting, but otherwise showed vibrational progression very similar to that observed for origin-excited bare Pc. Figure 6 shows significant parts of the LIF spectrum of HPc obtained upon increasing the vapor pressure of water in the jet. The lowestenergy transition is observed at $16233 \mathrm{~cm}^{-1}$ and has been assigned to the origin of the $\mathrm{S}_{0}-\mathrm{S}_{1}$ transition of the $\mathbf{H P c} /\left(\mathrm{H}_{2} \mathrm{O}\right)_{\mathrm{n}}$ complexes. It is shifted down in energy by $333 \mathrm{~cm}^{-1}$ relative to bare HPc, which contrasts with the $+119 \mathrm{~cm}^{-1}$ blue shift observed for the hydrate of Pc. The main vibronic transitions are observed at 137, 143, and $292 \mathrm{~cm}^{-1}$ from the origin and these frequencies are practically unchanged in comparison with $1 \mathrm{~A}^{\prime}, 2 \mathrm{~A}^{\prime}$ and $4 \mathrm{~A}^{\prime}$ vibrations of bare HPc (Table 1). An additional weaker band has been observed in the hydrate at $140 \mathrm{~cm}^{-1}$, which is reminiscent of a band at $144 \mathrm{~cm}^{-1}$ in bare molecule, tentatively assigned to a combination of out-of-plane modes $2 \mathrm{~A}$ " and 3A'. Figure 7 shows the SVLF spectra obtained for excitation into the $0-0$ band of the complex as well as into the bands at +143 and $+292 \mathrm{~cm}^{-1}$. The SVLF spectrum resulting from the excitation of the origin (Figure 7A) shows peaks at 142, 258, and $291 \mathrm{~cm}^{-1}$. They are in clear correspondence to the spectrum of bare HPc. However, no further fluorescence bands were observed above $300 \mathrm{~cm}^{-1}$, where bare HPc shows several transitions due to in-plane vibrations of the macrocycle (e.g., at 336, 712, 749, or $788 \mathrm{~cm}^{-1}$ ). Interestingly, such weak spectral activity in this region has been predicted by the simulation for trans 2 tautomer (Figure 4, bottom). Another noticeable feature of $\mathbf{H P c} / \mathrm{H}_{2} \mathrm{O}$ complexes is the red shift 
of the 0-0 transition in the LIF spectrum, which is opposite to that observed for the complexes of parent porphycene. Its value of $330 \mathrm{~cm}^{-1}$ is quite substantial, and also comparable to the energy difference between the absorption bands of both trans tautomers of HPc at room temperature (612 and $622 \mathrm{~nm}$, for trans 1 and trans 2 , respectively, i.e. $\sim 260 \mathrm{~cm}^{-1}$ ) ). While it may be a pure coincidence, it may also suggest that hemiporphycene complexed by molecule(s) of water is in a different tautomeric form (trans2) than the "normal", isolated one. Although interesting, this suggestion needs more detailed fluorescence studies, and possibly massselective jet experiments to verify the stoichiometry of observed water complexes.

Figures 6-7

\section{Summary}

Measurements of LIF spectra and fluorescence depletion spectroscopy have shown that only one form of HPc is present in supersonic jet in the ground and lowest electronically excited states. It has been assigned to the lowest energy tautomer, trans 1 , based on the analysis of the experimental LIF and SVLF spectra and their comparison with theoretically predicted spectra for both trans tautomers. The overall agreement between the experiment and the simulated spectra using trans 1 molecular structure is very good, regarding both the vibrational frequencies and relative intensities. The prominent bands in LIF (e.g. 138, 142, 293, 333, and $355 \mathrm{~cm}^{-1}$ ) and SVLF spectra (e.g. 140, 336, 712, 749, and $788 \mathrm{~cm}^{-1}$ ) can be assigned to fundamental in-plane vibrational modes of the macrocycle. The SVLF spectra obtained at different excitation energy excess showed no evidence for trans $1 \rightarrow$ trans 2 phototautomerization in the $\mathrm{S}_{1}$ state. Also, no signs of tunneling splitting have been detected.

The localization of the internal hydrogens in HPC, a behavior opposite to that observed in porphycene, may be caused by several factors. First, lower symmetry of HPc dictates the lack of a symmetric double minimum potential, which is a condition for perfect coherent 
tunneling observed in Pc. Moreover, all four nitrogen atoms in HPc are chemically nonequivalent, which makes a synchronous concerted double hydrogen transfer (the mechanism proposed for Pc) very unlikely. In turn, single hydrogen transfers in HPc involve cis tautomers, the energies of which are significantly higher than those of the trans forms.

While symmetry is important, it does not warrant efficient tautomerization, as exemplified by porphyrin, in which the two minima corresponding to isoenergetic trans tautomers are separated by a high energy barrier. The barrier is determined by the properties of intramolecular hydrogen bonds: weak in porphyrin, very strong in porphycene. HPc represents a case intermediate between these two, as indicated by the values of $\mathrm{NH}$ stretching frequencies. $^{41}$

We plan to continue investigations on the role of symmetry in tautomerization, tunneling in particular, by studying corrphycene, another porphyrin isomer. This molecule is formally of the same symmetry as $\mathbf{H P c}\left(\mathrm{C}_{s}\right)$, but it possesses two pairs of chemically equivalent inner cavity nitrogen atoms.

Another subject worthy of further studies relates to complexes HPc with water, or, possibly, alcohols. The shift of their 0-0 transition in comparison to that of the bare macrocycle, opposite to that observed in the case of porphycene, suggest an interesting possibility of switching from one tautomeric form to the other upon complexation. If corroborated, such an effect could be very attractive for investigating the details of intra- and intermolecular hydrogen bond interactions in the same molecule.

\section{Supplementary Material}

See Supplementary Material for the complete list of the calculated vibrational frequencies for both trans tautomers of HPc, and comparison of the experimental LIF spectrum with the simulated ones including Herzberg-Teller approximation. 


\section{Acknowledgments}

This work was supported by the Polish National Science Centre grant 2014/15/B/ST4/05020, the PL-Grid infrastructure and computing grant G17-14 from the Interdisciplinary Centre for Mathematical and Computational Modeling of the Warsaw University. A.Z., S.P. and M.G. also acknowledge support from the CNRS and the Polish Academy of Sciences for the "Programmes Internationaux de la Cooperation Scientifique" (PICS 6363). The experiments performed in Orsay were conducted at the Centre Laser de l'Université Paris Sud (CLUPS) and we thank Dr. Michel Broquier for assistance and helpful discussions. 

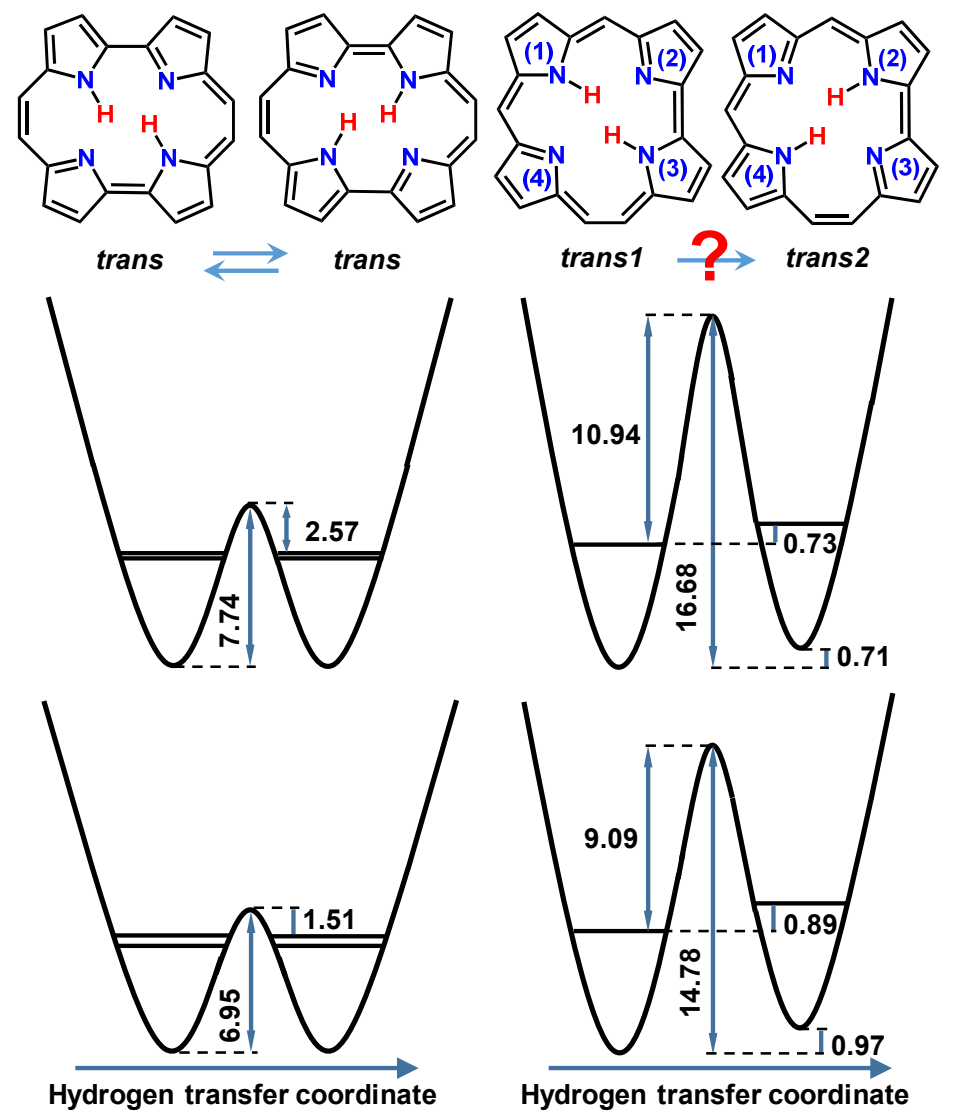

Figure 1. Molecular structures of two trans tautomers of Pc (left) and HPc (right), and their double minimum potential energy surfaces (PES) for a phototautomerization reaction between tautomers. The PES for a hypothetical trans $1 \rightarrow$ trans 2 reaction in HPc is asymmetric. Calculated barrier heights and energy level differences are given in $\mathrm{kcal} / \mathrm{mol}$. For details, see text. 


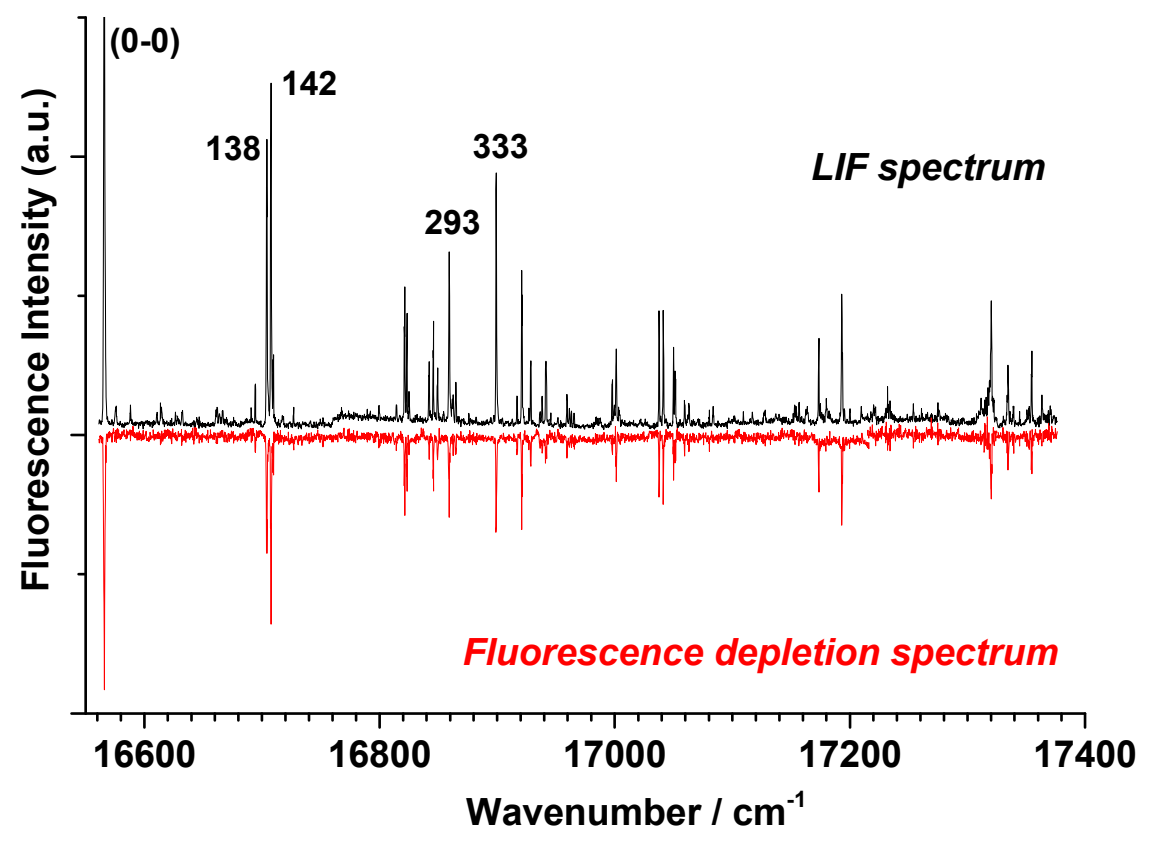

Figure 2. $L I F$ (top, black) and double resonance fluorescence depletion spectrum (bottom, red) of HPc obtained while pumping the 0-0 band at $603.64 \mathrm{~nm}\left(16566 \mathrm{~cm}^{-1}\right)$. 


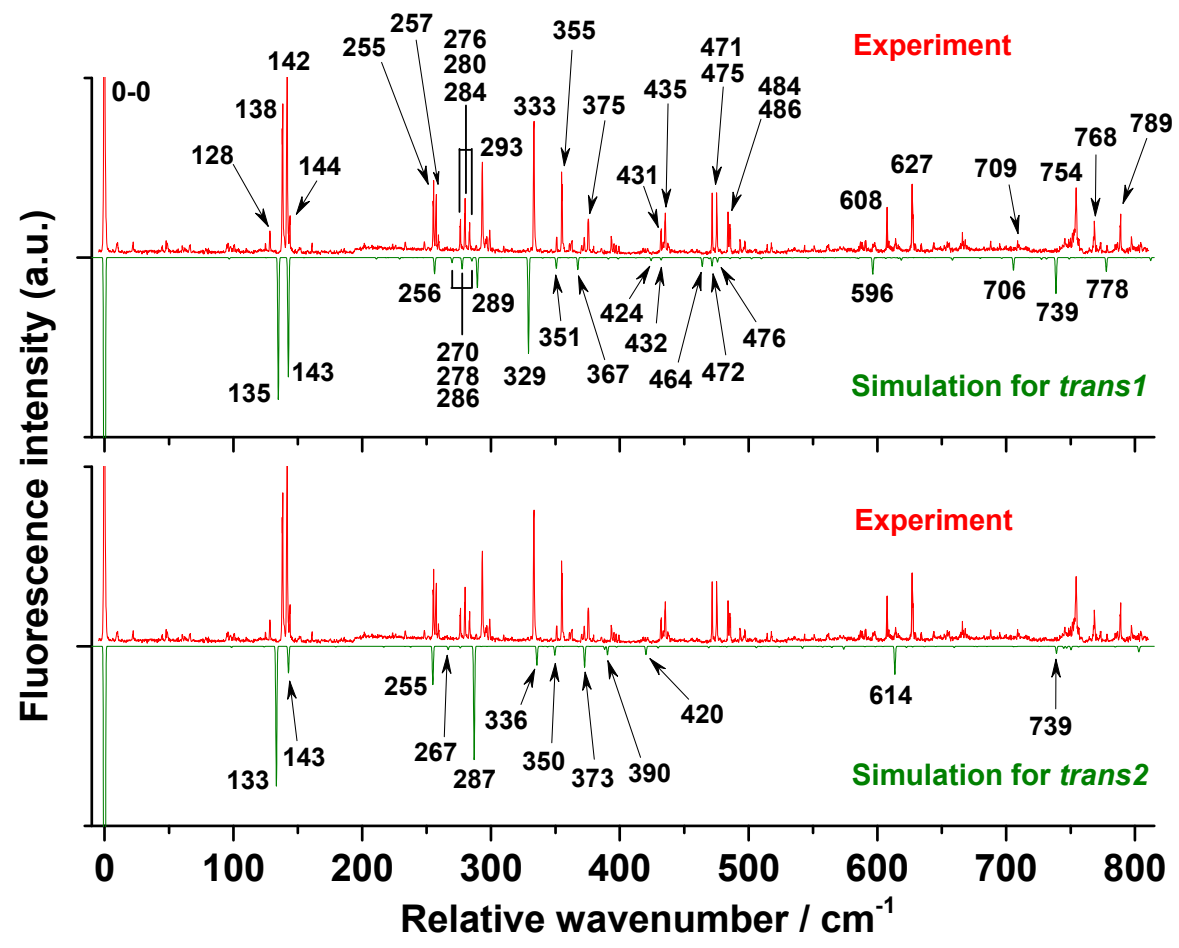

Figure 3. Experimental LIF spectrum of HPc (red) compared separately to simulated LIF spectra (green) of trans1 (top panel) and trans2 (bottom panel). For easier comparison, the intensity of the $0-0$ transitions has been divided by 2 for experimental LIF, and by 8 and 10 for trans 1 and trans 2 simulations, respectively. 


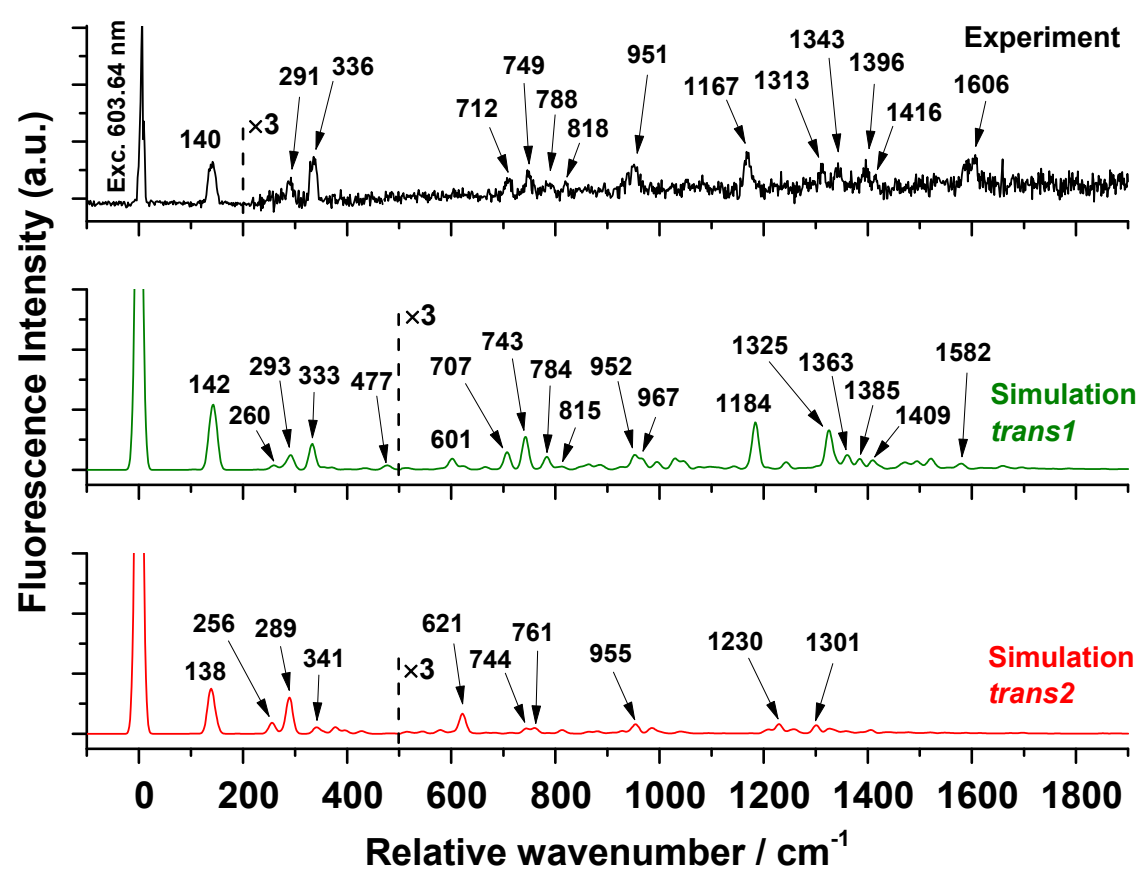

Figure 4. Experimental $S V L F$ spectrum of HPc (top, black) excited at the 0-0 band and the calculated SVLF spectra for trans 1 (middle, green) and trans2 (bottom, red) tautomers of HPc. For easier comparison, intensities in parts of the spectra have been magnified by a factor of 3 . 


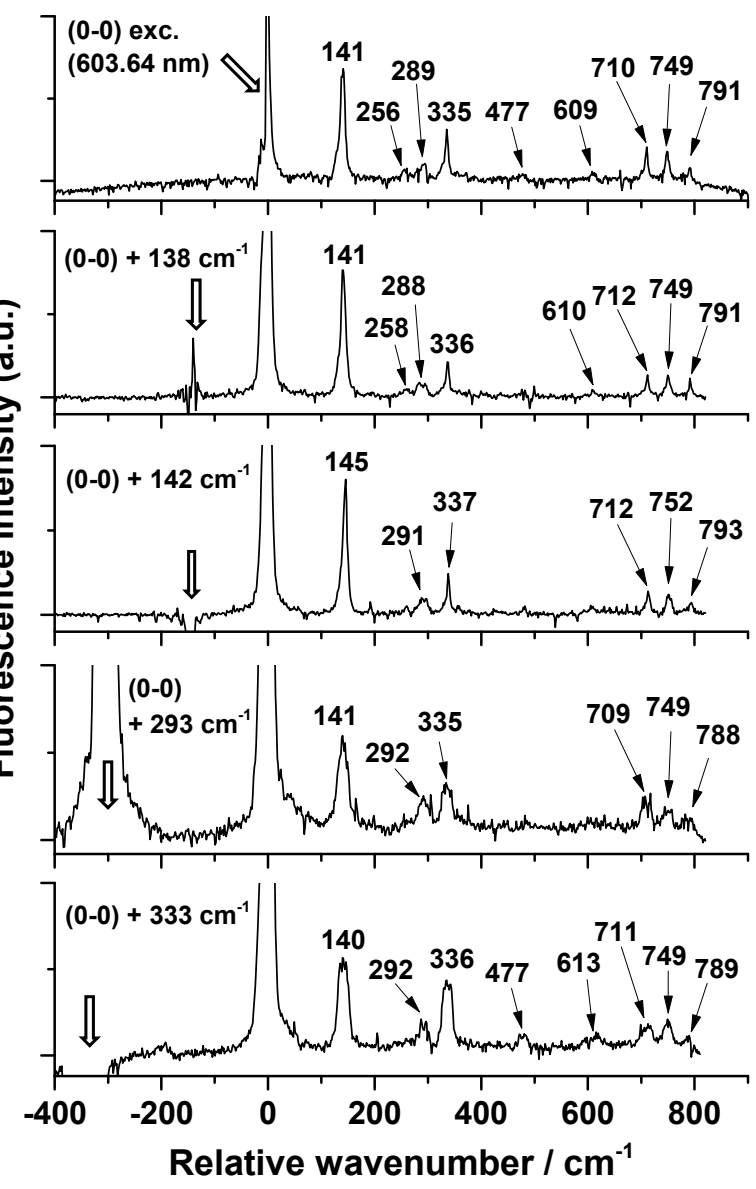

Figure 5. SVLF spectra of HPc recorded for excitation into the origin band $(603.64 \mathrm{~nm})$ and four other vibronic transitions at 138, 142, 293, and $333 \mathrm{~cm}^{-1}$. Band positions are given in wavenumbers relative to the $0-0$ band. 


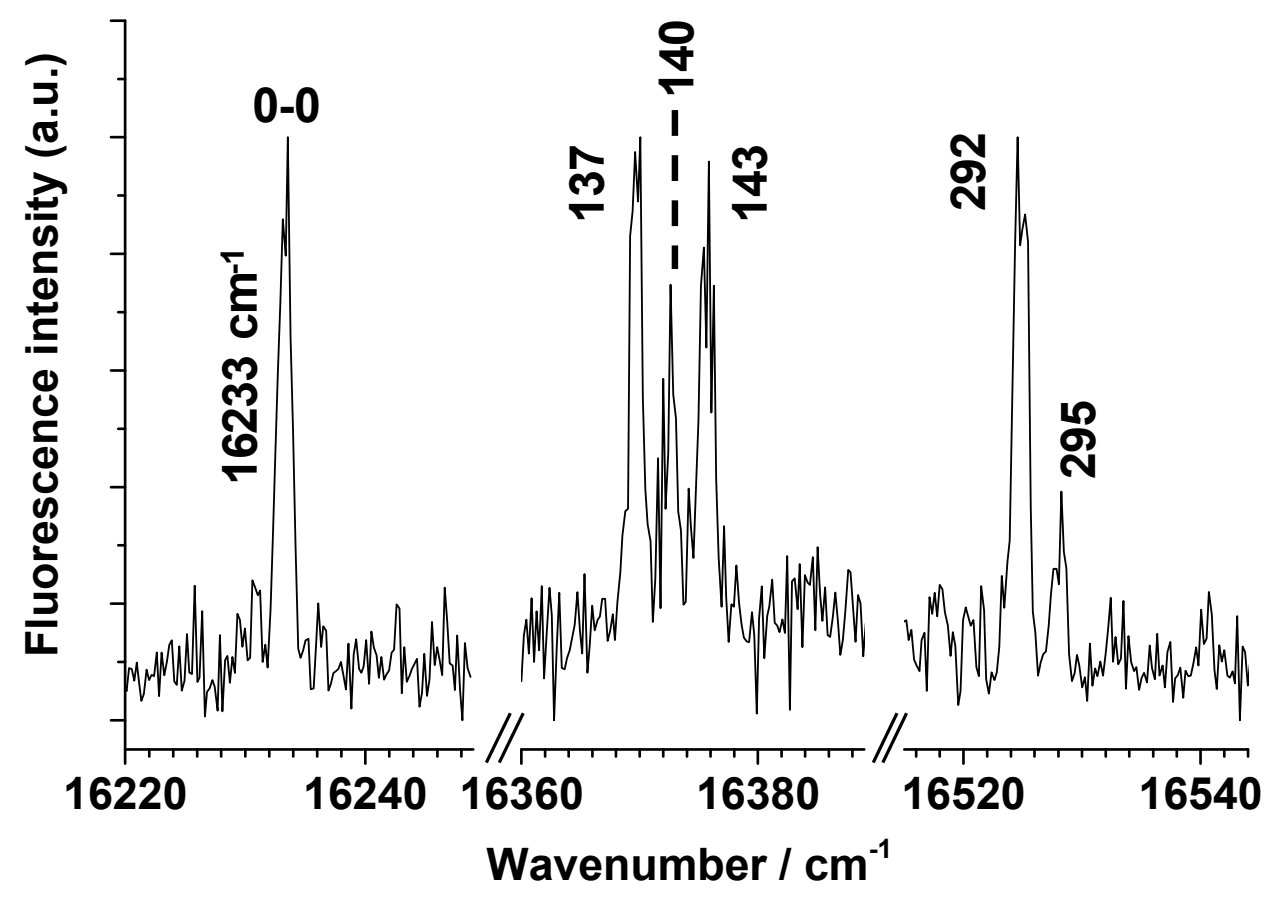

Figure 6. Part of LIF spectrum of HPc complex with water. Band positions are given in wavenumbers relative to the $0-0$ band. 

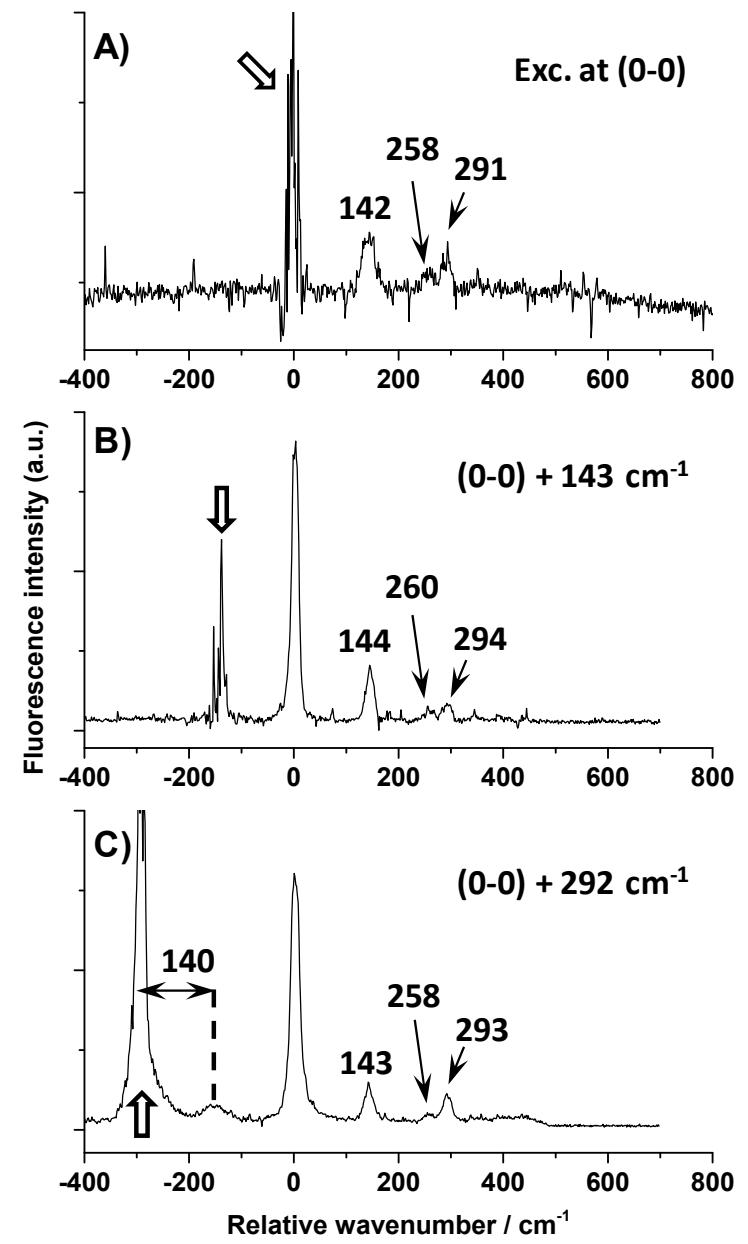

Figure 7. SVLF spectra of HPC complex with water upon excitation at (A) 0-0 band, (B) (0$0)+143 \mathrm{~cm}^{-1}$, (C) $(0-0)+292 \mathrm{~cm}^{-1}$. Band positions are given in wavenumbers relative to the 0-0 or pseudo $0-0$ band. 
Table 1. Ground and excited state $\left(S_{1}\right)$ vibrational frequencies of HPc obtained from LIF and SVLF spectra. Theoretically based frequencies correspond to those calculated for the trans 1 tautomer. For complete list of unscaled vibrations in both trans tautomers, see Supporting Information.

\begin{tabular}{|c|c|c|c|c|c|}
\hline$\tilde{\mathbf{v}}\left(\mathbf{S}_{1}\right) \exp$. & $\tilde{\mathbf{v}}\left(\mathbf{S}_{1}\right)$ calc. $^{\mathbf{a}}$ & Assignment $\mathrm{S}_{1}$ & $\tilde{\mathbf{v}}\left(\mathbf{S}_{0}\right) \exp$. & $\tilde{\mathbf{v}}\left(\mathbf{S}_{0}\right)$ calc. $^{\mathbf{a}}$ & Assignment $S_{0}$ \\
\hline 128 & 125 & $2 \times 2 A^{\prime \prime}$ & - & & \\
\hline 138 & 135 & $1 \mathrm{~A}^{\prime}$ & 140 & 138 & $1 \mathrm{~A}^{\prime}$ \\
\hline 142 & 143 & $2 \mathrm{~A}^{\prime}$ & & 146 & $2 \mathrm{~A}^{\prime}$ \\
\hline 144 & $140^{\mathrm{b}}$ & $2 A^{\prime \prime}+3 A^{\prime \prime}$ & - & & \\
\hline 255 & 256 & $3 A^{\prime}$ & 256 & 260 & $3 A^{\prime}$ \\
\hline 257 & $248^{\mathrm{b}}$ & $3 A^{\prime \prime}+6 A^{\prime \prime}$ & - & & \\
\hline 276 & 270 & $2 \times 1 A^{\prime}$ & - & & \\
\hline 280 & 278 & $1 A^{\prime}+2 A^{\prime}$ & - & & \\
\hline 284 & 286 & $2 \times 2 A^{\prime}$ & - & & \\
\hline 293 & 289 & $4 A^{\prime}$ & 291 & 293 & $4 \mathrm{~A}^{\prime}$ \\
\hline 333 & 329 & $5 \mathrm{~A}^{\prime}$ & 336 & 333 & $5 \mathrm{~A}^{\prime}$ \\
\hline 355 & 351 & $6 A^{\prime}$ & - & & \\
\hline 375 & 367 & $7 \mathrm{~A}^{\prime}$ & - & & \\
\hline 393 & 391 & $1 A^{\prime}+3 A^{\prime}$ & - & & \\
\hline 395 & 383 & $3 A^{\prime \prime}+6 A^{\prime \prime}+1 A^{\prime}$ & - & & \\
\hline 397 & 399 & $2 \mathrm{~A}^{\prime}+3 \mathrm{~A}^{\prime}$ & - & & \\
\hline 399 & 391 & $3 A^{\prime \prime}+6 A^{\prime \prime}+2 A^{\prime}$ & - & & \\
\hline 431 & 424 & $1 \mathrm{~A}^{\prime}+4 \mathrm{~A}^{\prime}$ & & & \\
\hline 435 & 432 & $2 \mathrm{~A}^{\prime}+4 \mathrm{~A}^{\prime}$ & - & & \\
\hline 471 & 464 & $1 A^{\prime}+5 A^{\prime}$ & 477 & 471 & $1 \mathrm{~A}^{\prime}+5 \mathrm{~A}^{\prime}$ \\
\hline
\end{tabular}




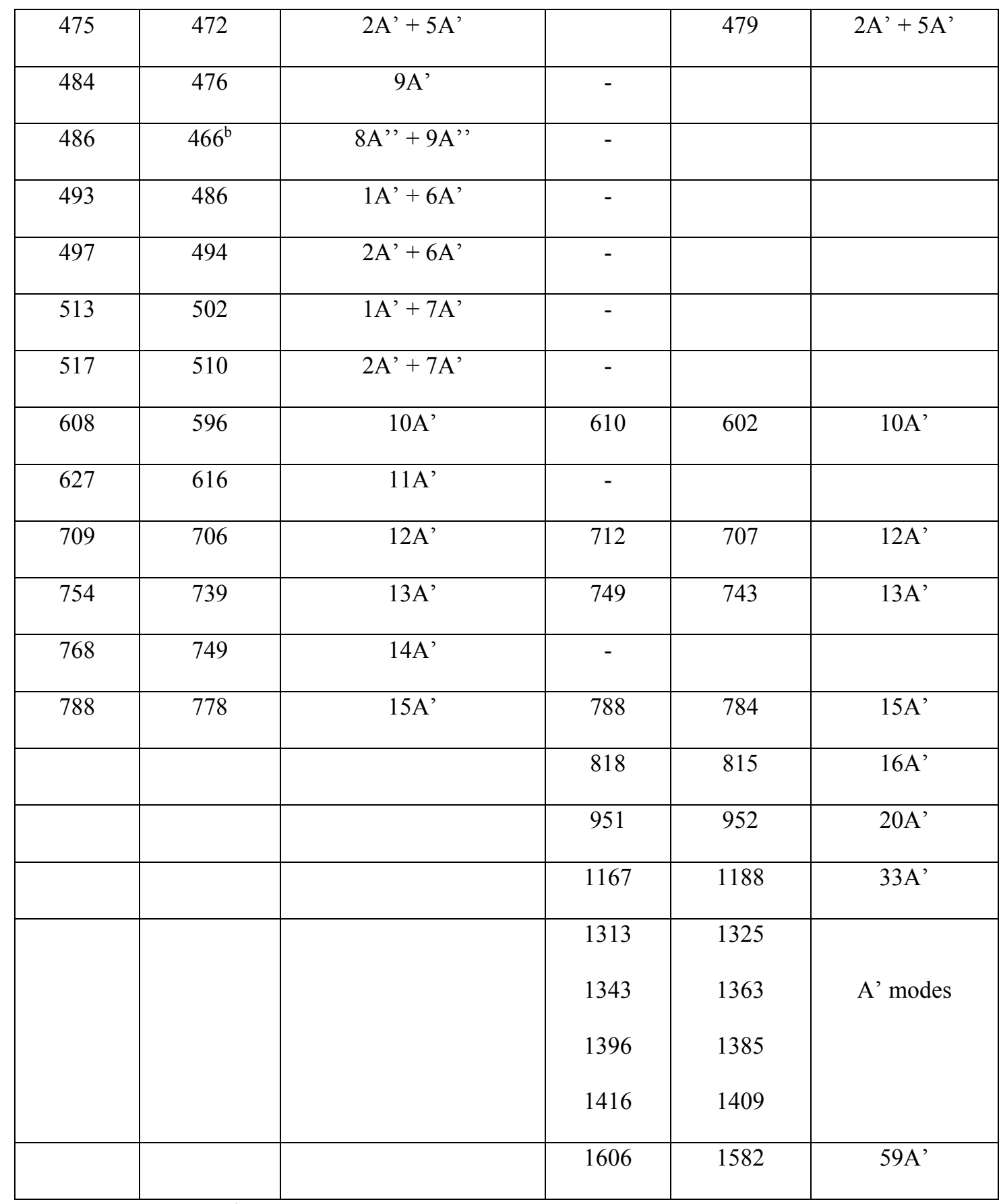

${ }^{\mathrm{a}}$ scaling factor $0.969,{ }^{\mathrm{b}}$ tentative assignment 


\section{References}

${ }^{1}$ J. Braun, H. H. Limbach, P. G. Williams, H. Morimoto, and D. E. Wemmer, J. Am. Chem. Soc. 118, 7231 (1996).

2 J. Braun, M. Schlabach, B. Wehrle, M. Köcher, E. Vogel, and H. H. Limbach, J. Am. Chem. Soc. 116, 6593 (1994).

${ }^{3}$ B. Wehrle, H. H. Limbach, M. Köcher, O. Ermer, and E. Vogel, Angew. Chem.-Int. Edit. Engl. 26, 934 (1987).

${ }^{4}$ J. M. L. del Amo, U. Langer, V. Torres, M. Pietrzak, G. Buntkowsky, H. M. Vieth, M. F. Shibl, O. Kühn, M. Bröring, and H. H. Limbach, J. Phys. Chem. A 113, 2193 (2009).

${ }^{5}$ A. Ghosh, and J. Almlöf J. Phys. Chem. 99, 1073 (1995).

${ }^{6}$ Y. D. Wu, K. W. K. Chan, C. P. Yip, E. Vogel, D. A. Plattner, and K. N. Houk, J. Org. Chem. 62, 9240 (1997).

${ }^{7}$ M. F. Shibl, M. Pietrzak, H. H. Limbach, and O. Kühn, ChemPhysChem 8, 315 (2007).

${ }^{8}$ M. F. Shibl, M. Tachikawa, and O. Kühn, Phys. Chem. Chem. Phys. 7, 1368 (2005).

${ }^{9}$ J. Waluk, Chem. Rev. 117, 2447 (2017).

${ }^{10}$ M. Koch, M. Pagan, M. Persson, S. Gawinkowski, J. Waluk, and T. Kumagai, J. Am. Chem. Soc. 139, 12681-12687 (2017).

${ }^{11}$ T. Kumagai, F. Hanke, S. Gawinkowski, J. Sharp, K. Kotsis, J. Waluk, M. Persson, and L. Grill, Nature Chem. 6, 41 (2014).

${ }^{12}$ H. Böckmann, S. Liu, J. Mielke, S. Gawinkowski, J. Waluk, L. Grill, M. Wolf, and T. Kumagai, Nano Lett. 16, 1034 (2016).

${ }^{13}$ J. Ladenthin, T. Frederiksen, M. Persson, J. Sharp, S. Gawinkowski, J. Waluk, and T. Kumagai, Nature Chem. 8, 935 (2016).

${ }^{14}$ P. Fita, L. Grill, A. Listkowski, H. Piwoński, S. Gawinkowski, M. Pszona, J. Sepioł, E. T. Mengesha, T. Kumagai, and J. Waluk, Phys. Chem. Chem. Phys. 19, 4921 (2017).

${ }^{15}$ P. Fita, N. Urbańska, C. Radzewicz, and J. Waluk, Chem.- Eur. J. 15, 4851 (2009).

${ }^{16}$ P. Ciąćka, P. Fita, A. Listkowski, C. Radzewicz, and J. Waluk, J. Phys. Chem. Lett. 7, 283 (2016).

${ }^{17}$ P. Ciąćka, P. Fita, A. Listkowski, M. Kijak, S. Nonell, D. Kuzuhara, H. Yamada, C. Radzewicz, and J. Waluk, J. Phys. Chem. B 119, 2292 (2015).

${ }^{18}$ M. Gil, and J. Waluk, J. Am. Chem. Soc. 129, 1335 (2007).

${ }^{19}$ M. Gil, J. Dobkowski, G. Wiosna-Sałyga, N. Urbańska, P. Fita, C. Radzewicz, M. Pietraszkiewicz, P. Borowicz, D. Marks, M. Glasbeek, and J. Waluk, J. Am. Chem. Soc. 132, 13472 (2010).

${ }^{20}$ H. Piwoński, C. Stupperich, A. Hartschuh, J. Sepioł, A. Meixner, and J. Waluk, J. Am. Chem. Soc. 127, 5302 (2005).

${ }^{21}$ H. Piwoński, A. Sokołowski, M. Kijak, S. Nonell, and J. Waluk, J. Phys. Chem. Lett. 4, 3967-3971 (2013).

${ }^{22}$ L. Piatkowski, C. Schanbacher, F. Wackenhut, A. Jamrozik, A. J. Meixner, and J. Waluk, J. Phys. Chem. Lett., 1211 (2018).

${ }^{23}$ J. Sepioł, Y. Stepanenko, A. Vdovin, A. Mordziński, E. Vogel, and J. Waluk, Chem. Phys. Lett. 296, 549 (1998).

${ }^{24}$ A. Vdovin, J. Sepioł, N. Urbańska, M. Pietraszkiewicz, A. Mordziński, and J. Waluk, J. Am. Chem. Soc. 128, 2577 (2006).

${ }^{25}$ A. Vdovin, J. Waluk, B. Dick, and A. Slenczka, ChemPhysChem 10, 761 (2009).

${ }^{26}$ E. T. Mengesha, A. Zehnacker-Rentien, J. Sepioł, M. Kijak, and J. Waluk, J. Phys. Chem. B 119, 2193 (2015).

${ }^{27}$ E. T. Mengesha, J. Sepioł, P. Borowicz, and J. Waluk, J. Chem. Phys. 138, 174201 (2013). 
${ }^{28}$ U. Even, and J. Jortner, J. Chem. Phys. 77, 4391 (1982).

${ }^{29}$ M. Gil, J. Jasny, E. Vogel, and J. Waluk, Chem. Phys. Lett. 323, 534 (2000).

${ }^{30}$ P. Fita, P. Garbacz, M. Nejbauer, C. Radzewicz, and J. Waluk, Chem.- Eur. J. 17, 3672 (2011).

${ }^{31}$ M. Duran-Frigola, R. Tejedor-Estrada, D. Sánchez-García, and S. Nonell, Phys. Chem. Chem. Phys. 13, 10326 (2011).

${ }^{32}$ P. Fita, M. Pszona, G. Orzanowska, D. Sánchez-García, S. Nonell, E. Vauthey, and J. Waluk, Chem.Eur. J. 18, 13160 (2012).

${ }^{33}$ J. L. Sessler, E. A. Brucker, S. J. Weghorn, M. Kisters, M. Schäfer, J. Lex, and E. Vogel, Angew. Chem. Int. Ed. 33, 2308 (1994).

${ }^{34}$ M. A. Aukauloo, and R. Guilard, New J. Chem. 18, 1205 (1994).

${ }^{35}$ H. J. Callot, B. Metz, and T. Tschamber, New J. Chem. 19, 155 (1995).

${ }^{36}$ E. Vogel, M. Bröring, S. J. Weghorn, P. Scholz, R. Deponte, J. Lex, H. Schmickler, K. Schaffner, S. E. Braslavsky, M. Müller, S. Pörting, C. J. Fowler, and J. L. Sessler, Angew. Chem. Int. Ed. 36, 1651 (1997).

${ }^{37}$ E. Vogel, P. Scholz, R. Demuth, C. Erben, M. Bröring, H. Schmickler, J. Lex, G. Hohlneicher, D. Bremm, and Y. D. Wu, Angew. Chem. Int. Ed. 38, 2919 (1999).

${ }^{38}$ P. J. Chmielewski, L. Latos-Grażyński, K. Rachlewicz, and T. Glowiak, Angew. Chem. Int. Ed. 33, 779 (1994).

${ }^{39}$ H. Furuta, T. Asano, and T. Ogawa, J. Am. Chem. Soc. 116, 767 (1994).

${ }^{40}$ T. D. Lash, A. D. Lammer, and G. M. Ferrence, Angew. Chem. Int. Ed. Engl. 50, 9718 (2011).

${ }^{41}$ J. Ostapko, K. Nawara, M. Kijak, J. Buczyńska, B. Leśniewska, M. Pietrzak, G. Orzanowska, and J. Waluk, Chem. Eur. J. 22, 17311 (2016).

${ }^{42}$ S. Gawinkowski, G. Orzanowska, K. Izdebska, M. O. Senge, and J. Waluk, Chem.- Eur. J. 17, 10039 (2011).

${ }^{43}$ A. Vdovin, J. Sepioł, J. M. Kauffman, and A. Mordziński, Chem. Phys. Lett. 296, 557 (1998).

${ }^{44}$ Y. Stepanenko, PhD Thesis, p. 33, Institute of Physical Chemistry PAS, Warsaw 2002.

${ }^{45} \mathrm{M}$. Frisch et al., (Gaussian, Inc., Wallingford CT, 2010). 